\title{
Dam Break and Flash Flood Prediction Case Study: Zhinvali Dam, Georgia
}

\author{
David Gurgenidze ${ }^{1}$, Givi Gavardashvili $^{2}$, Vugar Aliyev ${ }^{3}$, Adam Ujma ${ }^{4}$ \\ ${ }^{1}$ Georgian Technical University, Georgia \\ ${ }^{2}$ Ts. Mirtskhulava Water Management Institute of Georgian Technical University, Georgia \\ ${ }^{3}$ AMIR Technical Services LLC, Azerbaijan \\ ${ }^{4}$ Czestochowa University of Technology, Faculty of Civil Engineering, Poland
}

doi: https://doi.org/10.21467/abstracts.93.55

\begin{abstract}
The reason for the disruption of hydraulic facilities, including Zhinvali earth dam (Georgia) may be natural calamities (earthquake, storm, mudflow, etc.), technogenic factors (corrosion and collapse of the building structures, violation of water intake regimes, etc.), as well as sabotage and terroristic acts and use of arms destructing dams during the war. In case of distuption of a hazardous hydrodynamic plant, a 102-meterhigh Zhinvali earth dam in our case, destructing tsunami-type waves are formed potentially. The strength of the waves depends on the amount of water and wave velocity. Therefore, the hydrodynamic objects with great amount of water in their reservoirs and with a great difference between the heights of their head and tail races (high head), are hazardous in this respect.
\end{abstract}

A breakdown wave and great water mass can overwhelm everything on their way: buildings, premises and agricultural plots, and may result in victims and great material losses. Following the category of a safety risk of a hydraulic facility (technological, environmental or social) and by considering a safety declaration of a facility owner, the terms of a dam operation must be observed by means of a safe operation and checks of the terms of no-failure operation of the plant units and all auxiliary facilities, buildings and equipment. The risk assessment for Zhinvali earth dam, in addition to the above-mentioned methods, will use a model of Comprehensive Approach to Probabilistic Risk Assessment (CAPRA) (author: Professor Bilal Ayubi, USA) based on the Memorandum of Cooperation with Maryland University (USA) (2011) considering the quantitative assessment and examination of all expected risks and introduction of obtained results.

The work will describe the process of risk management as a set of coordinated and continuous consecutive actions in line with ISO 31000 Standard. The methods to predict the hydrodynamic parameters of a tsunamitype wave formed in case of possible accident of Zhinvali earth dam will be identified and the contours of the flooded areas (the territories of Dusheti and Mtskheta Municipalities and cities of Tbilisi and Rustavi (Georgia)) by considering relevant risk-factors will be evaluated. Figure 1 shows a longitudinal profile of a tsunami-type wave formed in case of disruption of Zhinvali earth dam.

The following are the initial data necessary for calculations of the parameters of the breach wave: The capacity of the reservoir:

$$
W_{R}=\frac{H_{R} S_{R}}{3} \text { Million } \mathrm{m}^{3}
$$

Slope of the river bottom:

$$
i=\frac{B_{w} h_{G}^{2}}{W_{R} M(M+1)}
$$

(C) 2020 Copyright held by the author(s). Published by AIJR Publisher in "Abstracts of The Second Eurasian RISK-2020 Conference and Symposium" April 12- 19, 2020, Tbilisi, Georgia. Jointly organized by AMIR Technical Services LLC, Georgian Technical University, Institute of Geography (Kazakhstan) and Russian Institute of Petroleum Geology and Geophysics. 
The Second Eurasian RISK-2020 Conference and Symposium

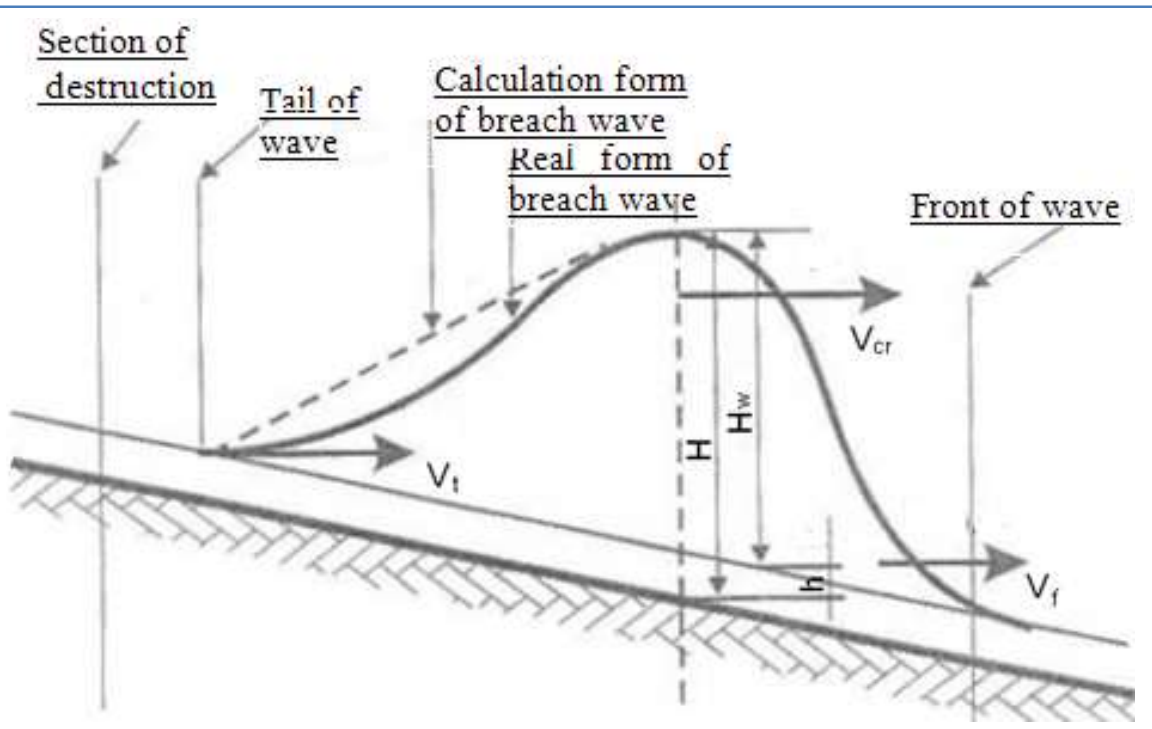

Fig. 1. Diagrammatic longitudinal section of a breach wave. $\mathrm{H}$ - ordinary level of water in the river; $\mathrm{h}-$ height of wave; $\mathrm{H}_{\mathrm{w}}$ - height of stream

The rate of wave $(V)$ at flooding in the tailrace of the structure is calculated by the following formula:

$$
V=V_{0}\left(H_{1} / H_{0}\right)^{2 / 3}
$$

The degree of destruction of the dam $\left(E_{P}\right)$ is determined by the following dependence:

$$
E_{p}=F_{W} / F_{0}
$$

where, $F_{w}$ - is the area of the collapse of the bank $\left(\mathrm{m}^{2}\right) ; F_{0}-$ is the area of the surface $\left(\mathrm{m}^{2}\right)$;

In addition to the above, considered in the algorithm are: the height $(\mathrm{m})$ of river bank, the number of section along length of the river, the distance between the sections $(\mathrm{km})$, width of the river bed $(m)$, the rate of the water stream in the river bed $(\mathrm{m} / \mathrm{sec})$; the width of bed of the river $(m)$, the value of the river bed marks $(m)$ etc. 